\title{
Corrosion Inhibition of Steel by Various Parts of Rotula Aquatica Plant Extracts in $\mathrm{H}_{2} \mathrm{SO}_{4}$ Solutions
}

\author{
Niketan S. Patel, ${ }^{a}$ Jiri Hadlicka, ${ }^{a}$ Pavel Beranek, ${ }^{a}$ Rachid Salghi, ${ }^{a,}$ \\ Houceine Bouya, ${ }^{b}$ Hassan A. Ismat, ${ }^{c}$ Belkheir Hammouti ${ }^{d}$ \\ ${ }^{a}$ Department of Chemical Engineering, The Institute of Chemical Technology, \\ Technická 5, Prague 6, Czech Republic \\ ${ }^{b}$ Equipe de Génie de l'Environnement et de Biotechnologie, ENSA, Université Ibn Zohr, \\ BP 1136, Agadir, Morocco \\ ${ }^{c}$ Chemistry Department of College of Science, King Khalid University, Abha, Saudi Arabia \\ ${ }^{d}$ LCAE-URAC18, Faculté des Sciences, Université Mohammed First, Oujda, Morocco
}

Received 9 November 2014; accepted 20 December 2014

\begin{abstract}
The corrosion inhibition and adsorption of ethanol extracts of leaves (LV), stems (ST) and roots (RT) of Rotula aquatica plant for mild steel in $\mathrm{H}_{2} \mathrm{SO}_{4}$ solutions were investigated using conventional weight loss, gasometric techniques, electrochemical polarizations and electrochemical impedance spectroscopy. The results showed that all the three extracts of Rotula aquatica plant performed well as inhibitor for the corrosion of steel in sulphuric acid media and the inhibition efficiencies of the extract follow the trend RT > LV > ST. Inhibition efficiencies increased with increasing concentration of the plant extracts but decreased with the temperature rise for all cases. Both the cathodic hydrogen evolution and the anodic dissolution of mild steel were inhibited, hence the active molecules of all the extracts studied acted as mixed type corrosion inhibitors.
\end{abstract}

Keywords: Rotula aquatic, corrosion inhibition, mild steel.

\section{Introduction}

The use of mild steel as construction materials in all industries is large and it poses a great challenge to prevent them from getting corroded. In addition, they are exposed to various corrosive environments including acids, alkalis and salts. Out of this, sulphuric acid is one of the most commonly used chemical in industries for removal of the undesired scales and rust. The addition of corrosion inhibitors is believed to be one of the best methods in these environments as they

\footnotetext{
* Corresponding author. E-mail address: r.salghi@uiz.ac.ma
} 
secure the metal against those severe acid attacks. Many studies in this regard using organic inhibitors have been reported. Most of the inhibitors are organic compounds with $\mathrm{N}, \mathrm{S}$ and $\mathrm{O}$ hetero-atoms having high electron density, making them reaction centers. These compounds are adsorbed on the metallic surface and block the active corrosion sites and most of them are highly toxic to both human beings and the environment. Hence, the use of natural products as eco-friendly and harmless corrosion inhibitors, has become popular [1-10]. The present work focuses on the application of various parts of Rotula aquatica plant extracts as a corrosion inhibitor of mild steel (MS) in $\mathrm{H}_{2} \mathrm{SO}_{4}$ medium. Here the ethanol extracts of leaves (LV), stems (ST) and roots (RT) of Rotula aquatica plant are prepared and studied by various techniques. Rotula aquatica is a Boraginaceae family plant originated from southern parts of India. There are reports available on phytochemical analysis of LV, ST and RT in various extracts of Rotula aquatica [11]. However, the leaves have never been exploited as a corrosion inhibitor in acid medium. Hence, the present work was aimed in this direction.

\section{Materials and methods}

\section{Preparation of herbal extract solutions}

About $500 \mathrm{~g}$ of dried and powdered samples of LV, ST and RT of Rotula aquatica were dried and powdered into a fine powder. These powder samples were extracted using absolute ethanol overnight. Initially, the extracts were concentrated using an evaporator and then dried on a steam both until a solid residue is obtained. By dissolving these solid residues, concentrations of 0.5, 1.0, 2.0, 3.0 and $4.0 \mathrm{~g} / \mathrm{L}$ were prepared.

\section{Preparation of electrodes}

As described above, three types of electrodes were used in the study. To prepare WE, MS rod sample $(0.09 \% \mathrm{P}, 0.37 \% \mathrm{Si}, 0.01 \% \mathrm{Al}, 0.05 \% \mathrm{Mn}, 0.19 \% \mathrm{C}, 0.06 \%$ $\mathrm{S}$ and the remainder $\mathrm{Fe}$ ) was obtained and carefully cut into many cylindrical electrodes. The upper area of the WE was then precisely covered with the Teflon and epoxy coating. The area of exposed surface of WE was measured precisely, with a Vernier caliper. For the weight loss method were used specimens (length $=2 \mathrm{~cm}$, width $=2 \mathrm{~cm}$, thickness $=0.1 \mathrm{~cm}$ ) with a tiny hole on their upper part.This prepared WE was washed with a lukewarm mild detergent (Surf) solution to remove greasy materials and then cleaned and washed repeatedly with double distilled water. It was quickly dried with a soft tissue paper and air dried then shifted into a desiccator or into the electrolyte in a polarization cell.

\section{Phytochemical screening}

Phytochemical screening was carried out on the extracts from Rotula aquatica by previously described method. The plant extracts were screened for alkaloids, saponins, tannins, flavonoids, terpenoids, steroids and quinones. 


\section{Weight loss and gasometric method}

The polished and pre-weighed MS specimens were tied with threads and suspended in $100 \mathrm{~mL}$ test solutions, $1 \mathrm{M} \mathrm{H}_{2} \mathrm{SO}_{4}$ with and without the inhibitor at different concentrations, for $24 \mathrm{~h}$ of immersion at temperatures of $30{ }^{\circ} \mathrm{C}, 40{ }^{\circ} \mathrm{C}$ and $50{ }^{\circ} \mathrm{C}$. The temperature was controlled by an aqueous thermostat. After the immersion test, the specimens were carefully washed in double-distilled water, dried and then weighed. The rinse removes loose segments of the film of the corroded samples. Duplicate experiments were performed in each set of the test and the mean value of the WL is reported. The loss in weight was determined by an analytic digital micro-balance. For the gasometric technique, high corrodent concentration is required; hence $5 \mathrm{M} \mathrm{H}_{2} \mathrm{SO}_{4}$ is used. In this technique, corrosion reactions in aqueous media are characterized by the evolution of a gas resulting from the cathodic reaction, which is proportional to the rate of corrosion. The rate of evolution of the gas $\left(\mathrm{R}_{\mathrm{H}}\right)$ is determined from the slope of the graph of volume of gas evolved $(\mathrm{V})$ versus time $(\mathrm{t})$.

$$
\begin{aligned}
& \theta=\frac{R_{H 0}-R_{H i}}{R_{H 0}} \\
& \eta=\frac{R_{H 0}-R_{H i}}{R_{H 0}} \times 100
\end{aligned}
$$

where $R_{H 0}$ and $R_{H i}$ are the rates of hydrogen evolution in the absence and presence of the plant extracts, respectively.

\section{Electrochemical and impedance measurements}

The AC impedance measurements are shown as Nyquist plots and polarization data as Tafel plots. The Electrochemical Analyzer Workstation (Autolab PGSTAT 302N) was employed for this purpose. Polarization curves were obtained with a scan rate of $0.01 \mathrm{~V} / \mathrm{s}$ in the range of $\pm 10 \mathrm{mV}$ for LPR and \pm 250 $\mathrm{mV}$ for TI vs. the $\mathrm{E}_{\text {corr }}$ of the WE of the MS and measured against the SCE. Impedance measurements were carried out at a constant value of $\mathrm{E}_{\text {corr }}$ after the electrode had been immersed for 60 minutes in the test solution. The frequency range applied was $0.1 \mathrm{~Hz}$ to $1000 \mathrm{~Hz}$. The A.C. signal was $5 \mathrm{mV}$ peak-to-peak with 12 data points per decade.

\section{Results and discussion}

Values of weight loss based on the WL measurements, $\mathrm{W}_{\text {corr }}$ and the $\mathrm{E}_{\mathrm{w}} \%$ for various concentrations of LV, ST and RT of Rotula aquatica extracts, after $24 \mathrm{~h}$ of immersion in $1 \mathrm{M} \mathrm{H}_{2} \mathrm{SO}_{4}$ are given in Table 1 . The following equation was used to determine the inhibition efficiency $\left(\mathrm{E}_{\mathrm{w}} \%\right)$ :

$$
E_{W} \%=100 \times \frac{W_{0}-W_{\text {corr }}}{W_{0}}
$$

where $\mathrm{W}_{\text {corr }}$ and $\mathrm{W}_{0}$ are the corrosion rates of steel with and without the additive, respectively. 
Table 1. Inhibition efficiency of MS in $1 \mathrm{M} \mathrm{H}_{2} \mathrm{SO}_{4}$ in presence and absence of different concentrations of Rotula aquatica extracts.

\begin{tabular}{ccccc}
\hline $\begin{array}{c}\text { Parts of Rotula } \\
\text { aquatica }\end{array}$ & Conc. $\mathbf{g} / \mathbf{L}$ & $\mathbf{W}\left(\boldsymbol{\mu g} / \mathbf{c m}^{2} \mathbf{h}\right)$ & $\mathbf{I E}(\boldsymbol{\%})$ & $\boldsymbol{\Theta}$ \\
\hline & Blanc & 17.25 & - & - \\
LV & 0.5 & 6.90 & 60 & 60 \\
& 1.0 & 6.01 & 65.15 & 0.6515 \\
& 2.0 & 5.11 & 70.38 & 0.7038 \\
& 3.0 & 4.05 & 76.52 & 0.7652 \\
& 4.0 & 3.51 & 79.65 & 0.7965 \\
\hline & 0.5 & 8.23 & 52.28 & 0.5228 \\
ST & 1.0 & 7.55 & 56.23 & 0.5623 \\
& 2.0 & 6.98 & 59.54 & 0.5954 \\
& 3.0 & 6.07 & 64.81 & 0.6481 \\
& 4.0 & 5.12 & 70.31 & 0.7031 \\
\hline & 0.5 & 5.40 & 68.70 & 0.6870 \\
RT & 1.0 & 4.74 & 72.52 & 0.7252 \\
& 2.0 & 3.97 & 76.99 & 0.7699 \\
& 3.0 & 3.17 & 81.62 & 0.8162 \\
& 4.0 & 2.31 & 86.60 & 0.8660 \\
\hline
\end{tabular}

From Table 1 it could be observed that the values of $\mathrm{E}_{\mathrm{w}} \%$ were gradually increased with the increase in concentration of all Rotula aquatica extracts. RT extracts achieved a maximum value of $86.60 \%$ IE at the highest concentration of $4.0 \mathrm{~g} / \mathrm{L}$. And according to the WL measurements the IE \% obtained followed the trend $\mathrm{RT}>\mathrm{LV}>\mathrm{ST}$. The degree of surface coverage $\theta$ at different concentrations of the additive in acidic media has been evaluated from WL using the equation:

$$
\theta=\frac{W_{0}-W_{\text {corr }}}{W_{0}}
$$

\section{Gasometric measurements}

The volume of hydrogen evolved during the corrosion of MS in $5.0 \mathrm{M} \mathrm{H}_{2} \mathrm{SO}_{4}$ solutions in the absence and presence of various parts of Rotula aquatica extracts was studied and the rates of hydrogen evolution were obtained. The rate of hydrogen evolution values are given in Table 2 and the difference of rate of hydrogen evolved for the different-concentrations of various parts of Rotula aquatic extract are shown in Fig 1.

The results attained Table 2 and Fig. 2 show that the inhibition efficiencies increase with increase in Rotula aquatica extracts (LV, ST and RT) concentration, and decrease slightly with increase in temperature. But the IE \% obtained followed the trend RT $>$ LV $>$ ST, proving that the active constituents present in the extracts play an important role and this differs for the different parts of the plant. Similar results have been obtained by the WL method at lower concentration of $\mathrm{H}_{2} \mathrm{SO}_{4}$ and at stable temperature condition. And the results of the above two methods prove that the active constituents of Rotula aquatica roots extracts performed the best as compared to the remaining two extracts. The rate of hydrogen evolved as a function of various concentrations of Rotula aquatica leaves extract is depicted in Fig. 3. 
Table 2. Results from hydrogen evolution technique (calculated values of the rate of hydrogen evolution, inhibition efficiency, activation energy, enthalpy change and entropy change for $\mathrm{MS}$ in $5.0 \mathrm{M} \mathrm{H}_{2} \mathrm{SO}_{4}$ solutions containing various parts of Rotula aquatica extracts)

\begin{tabular}{|c|c|c|c|c|c|c|c|c|c|c|}
\hline \multirow{2}{*}{$\begin{array}{c}\text { Parts of } \\
\text { Rotula } \\
\text { aquatica }\end{array}$} & \multirow{2}{*}{$\begin{array}{c}\text { Conc. of } \\
\text { inhibitor } \\
(\mathrm{g} / \mathrm{L})\end{array}$} & \multicolumn{3}{|c|}{$\begin{array}{l}\text { Rate of hydrogen evolution } \\
\qquad \mathrm{cm}^{3} / \mathrm{min} \text {. }\end{array}$} & \multicolumn{3}{|c|}{ Inhibition efficiency (\%) } & \multirow{2}{*}{$\underset{\mathbf{k J} / \mathbf{m o l}}{\mathbf{E a}}$} & \multirow{2}{*}{$\begin{array}{c}\Delta \mathbf{H}^{0} \\
\mathrm{~kJ} / \mathrm{mol}\end{array}$} & \multirow{2}{*}{$\begin{array}{c}\Delta \mathbf{S}^{\mathbf{0}} \\
\mathbf{J} \mathbf{m o l}^{-1} \mathbf{K}^{-1}\end{array}$} \\
\hline & & $30{ }^{\circ} \mathrm{C}$ & $40^{\circ} \mathrm{C}$ & $50^{\circ} \mathrm{C}$ & $30^{\circ} \mathrm{C}$ & $40^{\circ} \mathrm{C}$ & $50^{\circ} \mathrm{C}$ & & & \\
\hline \multirow{6}{*}{ LV } & Blank & 0.6 & 1.71 & 2.68 & - & - & - & 57.69 & -55.49 & -61.35 \\
\hline & 0.5 & 0.52 & 1.55 & 2.53 & 13.33 & 9.36 & 5.6 & 58.29 & -57.05 & -56.95 \\
\hline & 1.0 & 0.46 & 1.42 & 2.31 & 23.33 & 16.95 & 13.81 & 61.59 & -58.43 & -52.82 \\
\hline & 2.0 & 0.32 & 1.09 & 1.98 & 46.67 & 36.26 & 26.12 & 63.95 & -60.78 & -42.13 \\
\hline & 3.0 & 0.25 & 0.79 & 1.44 & 58.33 & 53.80 & 46.27 & 65.99 & -64.01 & -38.43 \\
\hline & 4.0 & 0.17 & 0.58 & 1.07 & 71.67 & 66.08 & 60.07 & 68.78 & -65.92 & -34.82 \\
\hline \multirow{5}{*}{ ST } & 0.5 & 0.55 & 1.61 & 2.56 & 8.33 & 5.85 & 4.48 & 61.35 & -60.07 & -56.39 \\
\hline & 1.0 & 0.49 & 1.47 & 2.41 & 18.33 & 14.04 & 10.07 & 62.82 & -61.27 & -51.68 \\
\hline & 2.0 & 0.37 & 1.18 & 2.07 & 38.33 & 30.99 & 22.76 & 64.78 & -62.83 & -49.14 \\
\hline & 3.0 & 0.31 & 0.95 & 1.57 & 48.33 & 44.44 & 41.42 & 65.26 & -65.15 & -46.63 \\
\hline & 4.0 & 0.22 & 0.71 & 1.20 & 63.33 & 58.48 & 55.22 & 67.75 & -67.19 & -45.98 \\
\hline \multirow{5}{*}{ RT } & 0.5 & 0.47 & 1.48 & 2.46 & 21.67 & 13.45 & 8.2 & 63.45 & -60.91 & -50.28 \\
\hline & 1.0 & 0.39 & 1.31 & 2.19 & 35 & 23.39 & 18.28 & 64.24 & -62.14 & -49.85 \\
\hline & 2.0 & 0.26 & 0.98 & 1.86 & 56.67 & 42.69 & 30.60 & 65.71 & -63.72 & -50.65 \\
\hline & 3.0 & 0.21 & 0.67 & 1.34 & 65 & 60.82 & 50 & 66.78 & -65.18 & -48.38 \\
\hline & 4.0 & 0.13 & 0.44 & 0.95 & 80 & 74.27 & 64.55 & 68.85 & -67.35 & -47.23 \\
\hline
\end{tabular}

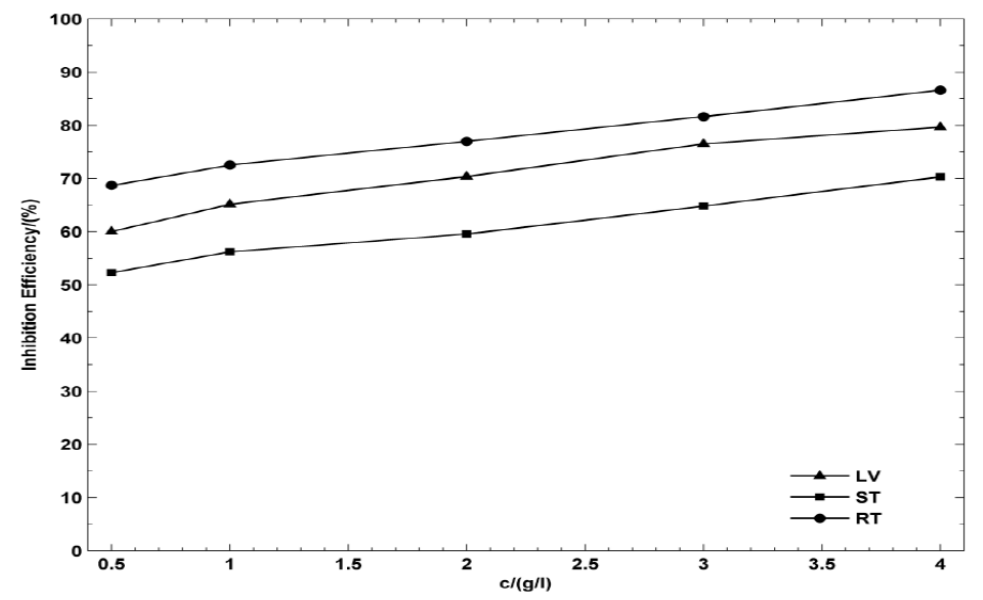

Figure 1. Inhibition efficiencies against the various concentrations of the extracts studied using WL method.

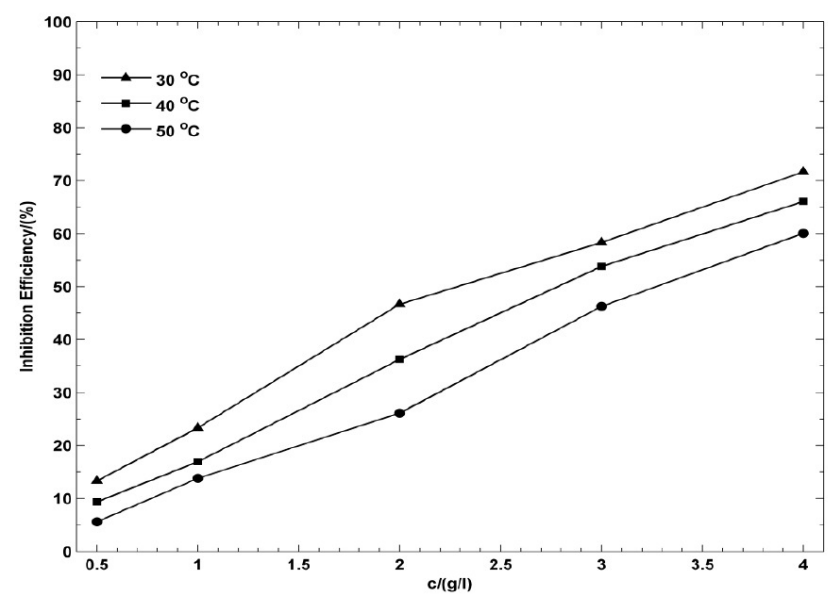

Figure 2. Inhibition efficiencies against the various concentrations of the extracts at various temperatures studied using the gasometric method. 


\section{Activation parameters}

The activation parameters for $\mathrm{MS}$ in $5.0 \mathrm{M} \mathrm{H}_{2} \mathrm{SO}_{4}$ solutions in the absence and presence of Rotula aquatica extracts were calculated from the Arrhenius-type plot equation 5 and the transition state equation 6 :

$$
\begin{aligned}
& k=A \exp \left(-E_{a} / R T\right) \\
& k=R T / N h \exp \left(\Delta S^{0} / R\right) \exp \left(-\Delta H^{0} / R T\right)
\end{aligned}
$$

where $R$ is the universal gas constant, $N$ is the Avogadro's number, $h$ is the Plank's constant, $E_{a}$ is the activation energy, $T$ is the absolute temperature, and $\Delta H^{0}$ and $\Delta S^{0}$ are the standard enthalpy and entropy of activation, respectively. In Fig. 4 again Rotula aquatica leaves extract is depicted and $\log$ of $\mathrm{RH}$ is plotted against 1/T for which gave straight lines. The activation energies are obtained from the slopes of the plots and listed in Table 2. From the results, it is observed that Ea values increased in presence of the plant extract in relation to the blank system. The average Ea value has been calculated as: $63.72 \mathrm{~kJ} / \mathrm{mol}$ (Rotula aquatica leaves extract), $64.40 \mathrm{~kJ} / \mathrm{mol}$ (Rotula aquatica stems extracts) and 65.81 $\mathrm{kJ} / \mathrm{mol}$ (Rotula aquatica roots extracts), which confirmed the physical adsorption mechanism. The enthalpy and the entropy of activation values for MS in $5.0 \mathrm{M}$ $\mathrm{H}_{2} \mathrm{SO}_{4}$ solutions obtained from linear square fit of $\log (R H / T)$ data versus $1 / T$ (Fig. 5) for Rotula aquatica various extracts are presented in Table 2.

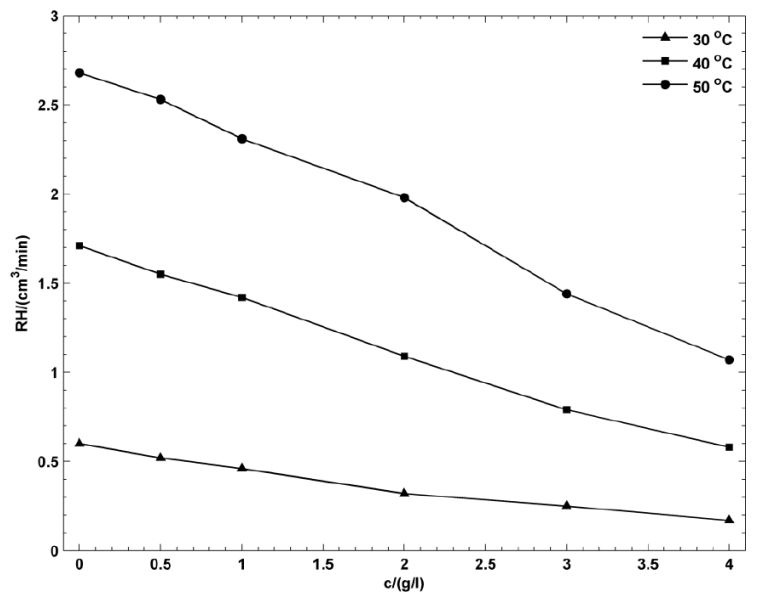

Figure 3. Rate of hydrogen evolved for the different concentrations of Rotula aquatica leaves extract in $5.0 \mathrm{M} \mathrm{H}_{2} \mathrm{SO}_{4}$ solutions using hydrogen evolution technique.

The negative values of $\Delta H^{0}$ obtained represent an exothermic adsorption process. This suggests either physical or chemical adsorption. Usually, the enthalpy of physical adsorption process is lower than $80 \mathrm{~kJ} / \mathrm{mol}$ while the enthalpy of chemisorption process approaches $100 \mathrm{~kJ} / \mathrm{mol}$. Hence, the $\Delta H^{0}$ values obtained confirm the physical adsorption of the plant extract constituents on the surface of MS. The negative $\Delta S^{0}$ values suggest that the activation complex in the rate determining step represents association rather than dissociation step $[12,13]$. 


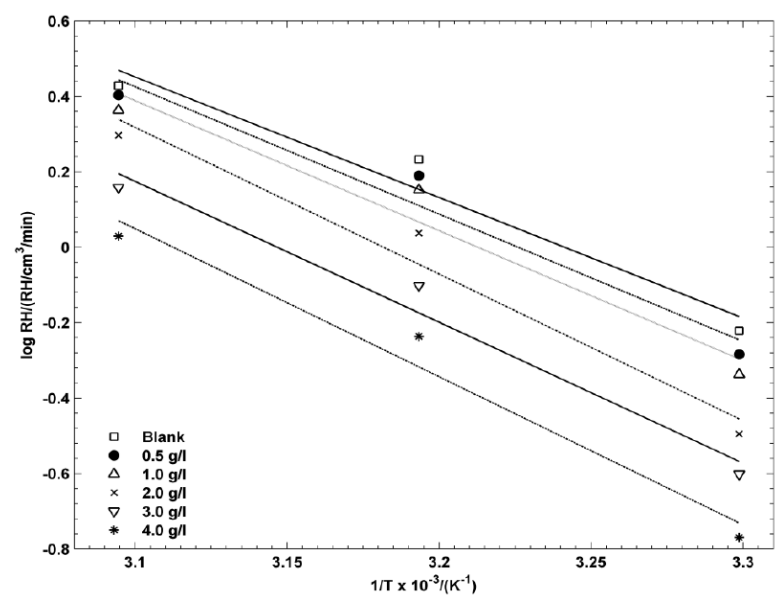

Figure 4. Arrhenius plot for $\mathrm{MS}$ in $5.0 \mathrm{M} \mathrm{H}_{2} \mathrm{SO}_{4}$ solutions containing Rotula aquatica leaves extract.

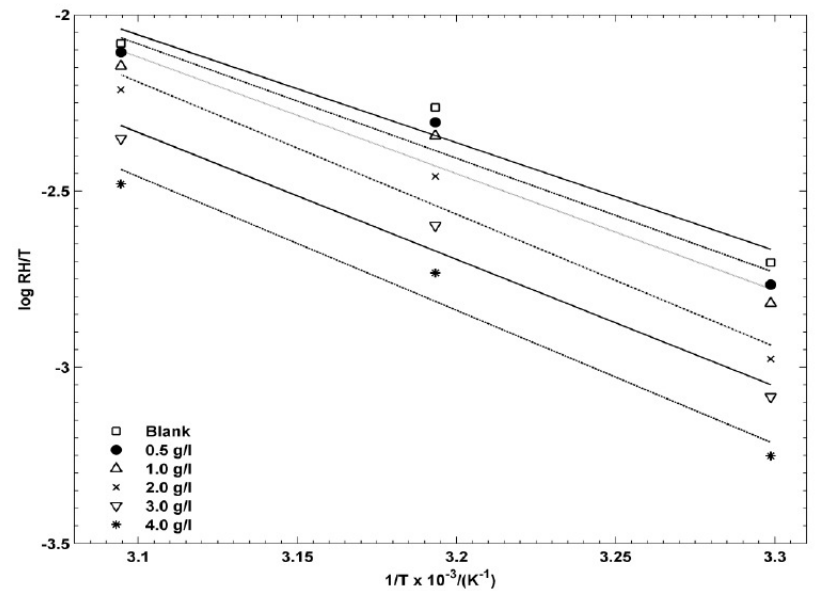

Figure 5. Transition state plot for $\mathrm{MS}$ in $5.0 \mathrm{M} \mathrm{H}_{2} \mathrm{SO}_{4}$ solutions containing Rotula aquatic leaves extract.

\section{Electrochemical polarizations}

The potentiodynamic polarization data are shown in Fig. 6 as the Tafel plots for MS in $1 \mathrm{M} \mathrm{H}_{2} \mathrm{SO}_{4}$ solutions with the addition of various concentrations of the additive. To avoid unnecessary overlapping and to get a better idea, two concentrations (2.0 and $4.0 \mathrm{~g} / \mathrm{L}$ ) of each LV, ST and RT of Rotula aquatica extracts are presented in the plots. The corrosion kinetic parameters such as $\mathrm{E}_{\mathrm{corr}}$, $I_{\text {corr }}$, anodic and cathodic Tafel slopes $\left(b_{a}\right.$ and $\left.b_{c}\right)$ were derived from these curves. From Fig. 6, it is observed that there was an anodic shift of the $\mathrm{E}_{\text {corr }}$ value for each (2.0 and $4.0 \mathrm{~g} / \mathrm{L}) \mathrm{LV}$, ST and RT of Rotula aquatica extracts, indicating that all the extracts acted as anodic inhibitors for MS in $1 \mathrm{M} \mathrm{H}_{2} \mathrm{SO}_{4}$ solutions which was supported by the gradual and significant decrease of anodic Tafel slope values. The measured $\mathrm{I}_{\text {corr }}$ values also found progressively decreasing with steady increase in the concentration of the additive up to $4.0 \mathrm{~g} / \mathrm{L}$. It could be derived from this decrease that the rate of anodic dissolution was much retarded in comparison to that of cathodic hydrogen evolution. There was only a little decrease in the corresponding values of cathodic Tafel slopes to show that the extract must have acted predominantly by blocking the anodic sites, and also the cathodic sites to some extent, and the extract containing the active molecules was 
adsorbed effectively and behaved as a mixed-type of the acid corrosion inhibitors.

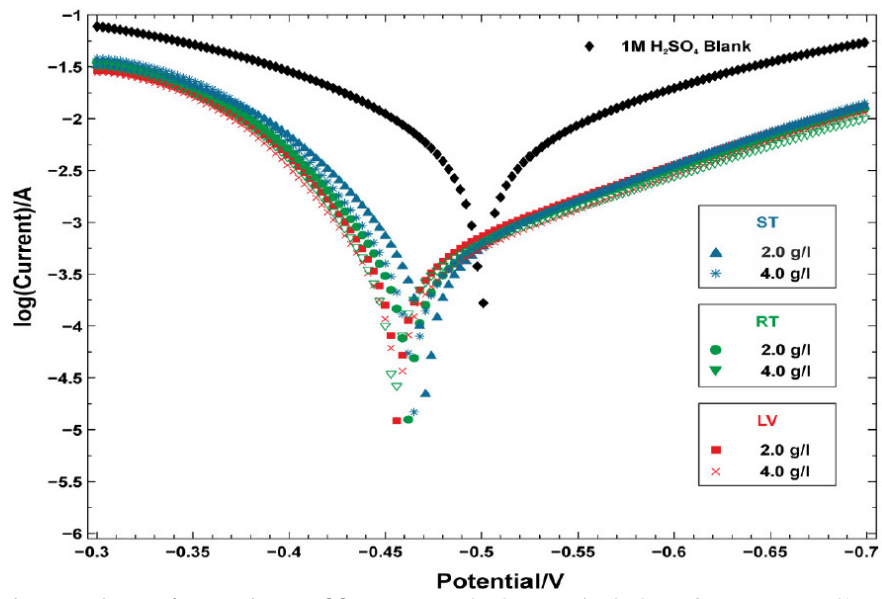

Figure 6. Tafel plots showing the effect at (2.0 and $4.0 \mathrm{~g} / \mathrm{L}) \mathrm{LV}, \mathrm{ST}$ and RT of Rotula aquatica extracts on corrosion of $\mathrm{MS}$ in $\mathrm{H}_{2} \mathrm{SO}_{4}$ solutions.

\section{Electrochemical impedance spectroscopy}

The corrosion measures of MS in $1 \mathrm{M} \mathrm{H}_{2} \mathrm{SO}_{4}$ solutions, in absence and presence of various concentrations of Rotula aquatica extracts were also investigated by EIS technique. The resultant Nyquist plots are shown in Fig. 7. Again, to avoid unnecessary overlapping and to get a better idea, two concentrations (2.0 and 4.0 $\mathrm{g} / \mathrm{L})$ of each LV, ST and RT of Rotula aquatica extracts are presented in the plots. There was a gradual increase in the diameter of each semicircle of the Nyquist plots and this increase of the diameters has clearly shown that the $R_{t}$ values were also increased remarkably as compared to the blank, and that may be due to the formation and gradual improvement in compactness of the barrier layer of the inhibitive molecules adsorbed, and as a result the acid corrosion rates of MS were steadily decreased.

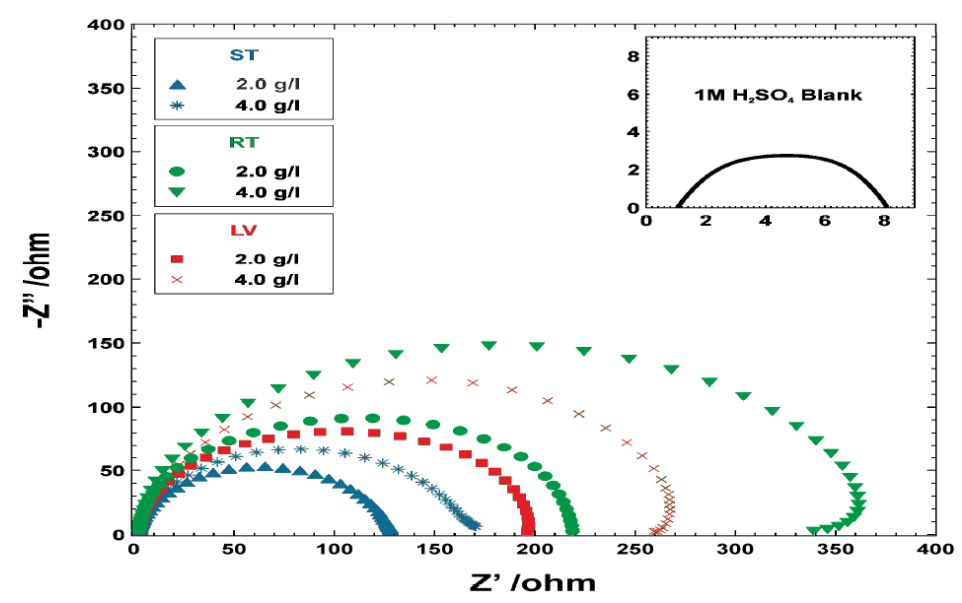

Figure 7. Nyquist plots showing the effect at (2.0 and $4.0 \mathrm{~g} / \mathrm{L}) \mathrm{LV}, \mathrm{ST}$ and RT of Rotula aquatica extracts on corrosion of $\mathrm{MS}$ in $\mathrm{H}_{2} \mathrm{SO}_{4}$ solutions.

Here also the RT extracts of Rotula aquatica plant clearly outperformed LV and ST extracts by attaining the highest charge transfer resistance values and 
achieving almost 98\% IE. The stability of the barrier layer formed by the adsorbed molecules of LV, ST and RT of Rotula aquatica extracts was very good when there were no DC polarizations exerted in AC Impedance method, but in the WL and gasometric measurements, when the highest temperature of $50{ }^{\circ} \mathrm{C}$ and the DC polarizations at ambient temperature were carried out, the stability of the layers was considerably decreased due to removal of the loosely adsorbed molecules on the steel surface.

\section{Conclusions}

The active molecules present in the extracts of LV, ST and RT of Rotula aquatica plant have effectively inhibited corrosion of $\mathrm{MS}$ in $1 \mathrm{M} \mathrm{H}_{2} \mathrm{SO}_{4}$ by forming a protective barrier layer. The inhibition efficiency of the extract increased gradually with increase in its concentration. Polarization measurements have shown that the extract of LV, ST and RT of Rotula aquatica plant has acted as a mixed type corrosion inhibitor, retarding mainly anodic dissolution of steel in $1 \mathrm{M} \mathrm{H}_{2} \mathrm{SO}_{4}$. The results of the weight loss, gasometric measurements, electrochemical polarization and AC impedance spectroscopy were all in very good agreement to support the above conclusions.

In addition, for all the methods studied for the various parts of Rotula aquatica plant followed the trend of RT $>$ LV $>$ ST. Key reason for this could be the high concentration of phytochemical constituents in those parts, mainly alkaloids.

\section{References}

1. Bouyanzer A, Hammouti B. Bull Electrochem. 2004;20:63-65.

2. Dahmani M, Et-Touhami A, Al-Deyab SS. et al. Int J Electrochem Sci. 2010;5:1060-1069.

3. Bammou L, Mihit M, Salghi R, et al. Int J Electrochem Sci. 2011;6:14541467.

4. Zerga B, Sfaira M, Rais Z, et al. Materiaux Technique. 2009;97:297-305.

5. Chaieb E, Bouyanzer A, Hammouti B, et al. Acta Phys Chim Sin. 2009;25:1254-1258.

6. Patel NS, Jauhari S, Mehta GN, et al. Int J Electrochem Sci. 2013;8:26352655.

7. Patel NS, Jauhari S, Mehta GN, et al. J Iran Chem Soc. 2012;9:635-641.

8. Akalezi CO, Enenebaku CK, Oguzie EE. J Mater Environ Sci. 2013;4:217226.

9. Benali O, Benmehdi H, Hasnaoui O, et al. J Mater Environ Sci. 2013;4:127138.

10. Ramananda SM. J Mater Environ Sci. 2013;4:117-126.

11. Vijayakumari B, Sasikala V, Radha SR. Pharmace Sci. 2013;2:6371- 6380.

12. Okafor PC, Ebenso EE. Pigm Res Tech. 2007;36:134-140.

13. Okafor PC, Ebenso EE, Ekpe U. Bull Chem Soc Ethiop. 2004;18:181-192 